Cadernos de Clio, Curitiba, n. ${ }^{\circ}$ 2, 2011

\title{
Notas sobre o neonazismo no site Extreme Violent Racism
}

\author{
Pedro Carvalho Oliveira ${ }^{1}$
}

Resumo: O trabalho busca compreender como o fascismo vem ressurgindo no tempo presente e como este discurso extremista tem sido difundido atualmente, assim como observar de que maneira os grupos voltados para estas ideias se apropriam da Internet para expor propagandas violentas contra os opositores deste pensamento. Para tanto, analisaremos o site norte-americano Extreme Violent Racism (http://www.whitehonor.com/), que em suas páginas utilizam de apelos de todos os tipos para angariar adeptos tentando convencê-los da necessidade de tornarem-se nacional-socialistas.

Palavras-chave: neonazismo; fascismo; História do tempo presente; Internet.

\section{Introdução}

O fim da Segunda Guerra Mundial não sepultou o fascismo, ao contrário do que muitos pensavam e pensam até os dias de hoje. No mundo inteiro, diversas manifestações a favor do nacionalsocialismo hitlerista e das ideias de Benito Mussolini podem ser observadas, como na Alemanha, onde, de acordo com fontes oficiais,

1 Graduando em História pela Universidade Federal de Sergipe. Bolsista do Programa de Educação Tutorial (PET/História/UFS) e membro do Grupo de Estudos do Tempo Presente (CNPq/UFS). Orientador: Prof. Dr. Dilton Cândido Santos Maynard. E-mail: Pedro@getempo.org. 
aproximadamente 80 grupos, reunindo cerca de 68 mil pessoas, tinham o potencial para serem classificadas como militantes fascistas, no final do século XX (SILVA, 2004). A Internet, mecanismo que desde a década de 1990 tem ganhado força na sociedade de informação, tem se tornado uma ferramenta essencial para a propaganda extremista, uma vez que alcança o mundo inteiro e facilita a expansão destes ideais. O site Extreme Violent Racism (http://www.whitehonor.com/), sobre o qual nos debruçaremos, é uma prova de que a extrema-direita ganha força com a rede mundial de computadores.

O Grupo de Estudos do Tempo Presente (GET/UFS/CNPq), da Universidade Federal de Sergipe, e a pesquisa vinculada a ele, intitulada "Intolerância Digital: história, extrema-direita e cibercultura (1999-2009)", buscou durante um ano investigar e catalogar sites ligados à extrema-direita, realizar leituras a respeito deste tema e apresentar trabalhos como resultado destes estudos, a fim de trazer a público aspectos do mundo neonazista durante uma década. A pesquisa também buscou conhecer mais proximamente o plano em que estas informações pairam, a internet, sua cultura particular e de que forma ela vem sendo utilizada por estes grupos. Para a História, esta pesquisa pode auxiliar na compreensão do ressurgimento do fascismo e da força que tem ganhado através dos 
anos, afastando-o da idéia de que esta ideologia ficou no passado, e que é possível observá-la no tempo presente, momento no qual se foca esta vertente historiográfica que tanto tem gerado discussões a respeito de sua validade científica.

Antes de adentrarmos nas informações resultantes da pesquisa no site Extreme Violent Racism, tentaremos esclarecer os propósitos de estudar o tempo presente, sua necessidade, sua metodologia, e de que forma ela está associada ao tema aqui proposto, além de transitarmos num breve reconhecimento do mundo virtual, onde as fontes para este estudo estão disponíveis.

\section{Estudo do tempo presente - jornalismo ou história?}

O surgimento de uma história do presente, no final da Segunda Guerra Mundial, serve à necessidade de compreender os diversos precedentes e resultados deste acontecimento na Europa. Fenômenos políticos como o nazismo e o fascismo apareciam como importantes objetos de estudo, uma vez que se fazia necessário entender as razões pelas quais estas políticas chegaram ao poder, para que, desta forma, se evitasse que pudessem fazê-lo novamente; os diversos países que participaram da guerra agora ganhavam novas faces que seriam apresentadas para o mundo: a Alemanha, derrotada e culpada pela guerra de um lado, e a França, triunfante em sua 
vitória, de outro, entre outras ocorrências, levaram à necessidade de um estudo daquele período, mesmo que, para o historiador, encarregado deste exame, não houvesse o recuo temporal necessário exigido pela metodologia tradicional de sua ciência (LAGROU, 2009).

Graças a esta exigência metodológica, esta vertente historiográfica vem sendo alvo de críticas no universo acadêmico devido a uma confusão existente quanto a uma possível semelhança com o jornalismo, em razão de sua análise estar direcionada a acontecimentos muito recentes, estando o historiador dedicado a esta modalidade de história muito próximo de seu objeto de estudo, presenciando seus desdobramentos "no calor do momento" (LAGROU, 2009). Esta confusão existe devido a um perfil conservador inspirado pelo historicismo, em que se procura afirmar que para que o historiador seja imparcial e examine seu objeto de estudo sem se envolver com ele (o que por si só é impossível, admitem até mesmo alguns dos autores mais conservadores), faz-se necessário um afastamento temporal para que as informações obtidas sobre este objeto sejam devidamente recolhidos e possuam, também, uma qualidade quantitativa. Para Robert Frank,

há imediatismo entre o historiador do presente e a testemunha, e é preciso tirar partido disso. Mas o dever 
Cadernos de Clio, Curitiba, n. ${ }^{\circ}$ 2, 2011

do historiador consiste em criar uma mediação entre o depoimento e ele. Eis porque a noção de "história imediata" é sem dúvida criticável. A mediação é necessária. Ela deve ser construída, e passa pela reflexão crítica sobre o tempo e pela colaboração do depoimento na perspectiva da espessura da duração, aquela do passado próximo e longínquo. É essa consideração do longo termo que faz a diferença fundamental entre a "história do presente" e o trabalho sobre a "atualidade, entre o historiador e o jornalista. (FRANK, 1999, p. 117)

Vemos que, por se tratar de uma história dos acontecimentos recentes, a história do presente se assemelha ao jornalismo, que é imediato aos acontecimentos, sejam eles quais forem: políticos, sociais, econômicos etc. Entretanto, a diferenciação entre o jornalista e o historiador pode ser simplesmente observada: enquanto as notícias trazidas pelos jornais exibem as informações mais simples e menos aprofundadas dos acontecimentos, tendendo para uma superficialidade, insuficiente para a história, o historiador buscará confrontar as mais diversas informações visando alcançar uma conclusão que seja a mais próxima possível dos acontecimentos, explicando-os, então, ainda que muito próximo dos acontecimentos; a diferença entre o jornalista e o historiador do tempo presente é o tratamento que ambos dão às informações, e para que exista esta diferença, o historiador apóia-se numa metodologia de pesquisa. 
Cadernos de Clio, Curitiba, n. ${ }^{\circ} 2,2011$

Este perfil metodológico que obriga o historiador a estudar somente o passado distante é visto pelos historiadores do presente como ultrapassado e inadequado aos rumos que esta ciência tomou após 1945 .

Já se foi o tempo em que se acreditava que, quanto mais distante de nós, mais científica poderia ser a História. Vivíamos ainda o mito da História positivista, aquela que "fazia os documentos falarem", como se História não fosse uma articulação entre o nosso olhar e o acontecido. Não que eu aceite a idéia de esquecer o passado remoto. Fingir que filósofos gregos, profetas hebreus, legisladores romanos ou papas medievais não nos influenciaram é ingênuo e tolo. Como ingênuo e tolo é tentar estudar o tempo presente de forma a-histórica, apenas pelo noticiário televisivo ou de rádio, com suas fórmulas batidas e levianas (PINSKY, 2007, p. 8).

Portanto, o historiador do presente envolve-se com seu estudo de uma maneira maior, afastando-se do positivismo que negava essa possibilidade, na tentativa de realizar uma crítica mais adequada ao seu objeto de estudo: os acontecimentos recentes. Tomar cuidado para que estes acontecimentos sejam adequados ao perfil de fato histórico é indispensável ao pesquisador, devendo ele produzir conhecimento, e não apenas informação, objetivo único do jornalismo (PINSKY, 2007). 
Mas, por outro lado, um tratamento adequado das fontes pesquisadas exige que o historiador constitua uma metodologia para organizar suas informações. Esta sistematização das informações permitirá ao pesquisador uma precisão essencial para o avanço de seu trabalho, além de permitir a coleta de uma significativa quantidade de elementos constituintes de seu objeto de pesquisa e produzir conhecimento através delas, como um resultado final. Este processo envolve aquilo que chamamos de "método histórico", que

\footnotetext{
é "a constelação de regras do pensar o passado". As regras indicam os processos pelos quais o passado humano é contemporizado como história. Ao longo do desenvolvimento do pensar histórico, foram sendo consolidados os pontos referenciais de sua regulamentação nos mais diferentes paradigmas metodológicos (DIEHL, 2001, p. 21)
}

Ou seja, a pesquisa histórica deve obedecer alguns princípios para que possua um sentido, para que seu resultado alcance o objetivo previsto. Dentre estes princípios, a crítica ao objeto de estudo, sua interpretação em seus diversos níveis, dentre outros, assumem o papel de regra para que seja possível determinar as direções da pesquisa a um resultado satisfatório. Em nossa pesquisa, a catalogação dos sites visitados, utilizando o sistema CODEX, um site (www.codexbrasil.org) que permite cadastrar e controlar links da Internet, descrevendo-os e inserindo informações 
sobre seu funcionamento, nos permite acessar as informações contidas neles para observar com detalhes como se articula a expansão de idéias fascistas no meio virtual, conhecendo seus hábitos, costumes e a forma como se comportam na rede mundial de computadores. Esta catalogação, além dos downloads das próprias páginas, utilizando o programa WinHTTrack, capaz de realizar esta função, nos permite acumular dados para posterior leitura, crítica e interpretação de informações que nos levem a um conhecimento cada vez mais abrangente destes grupos.

Aquilo que vimos nos sites pesquisados foi confrontado com as leituras a respeito do assunto, disponibilizadas pelo orientador, para que a crítica das informações disponíveis na rede fosse assegurada, uma vez que existe um preconceito por parte de alguns historiadores quanto à integridade das fontes encontradas na Internet que, em razão do fácil acesso e possibilidade de inserção de informações por qualquer indivíduo, acabam caindo em certo descrédito.

\section{Internet e História - A Web Como Fonte Para O Historiador}

O surgimento da Internet na década de 1960, como um mecanismo de defesa militar durante a Guerra Fria (1945 a 1991), aproximou homens de máquinas, uma vez que esta relação era 
Cadernos de Clio, Curitiba, n. $^{\circ}$ 2, 2011

necessária para o desenvolvimento tecnológico em demanda na época, enquanto Estados Unidos e seus aliados do bloco capitalista e a União Soviética ao lado dos demais países socialistas tentavam superar um ao outro neste âmbito (BRABROOK, 2009). O aparecimento desta relação deu origem a uma linguagem específica para que a comunicação entre homens e computadores pudesse existir. Os elementos designativos dos componentes virtuais dos computadores e todo seu comportamento interativo, ou seja, seu mundo próprio, são chamados de cibercultura. Como explica Erick Felinto:

A cibercultura assinala sua especificidade com base nesse novo modelo tecnológico [digital], cujas características seriam inteiramente distintas do modelo anterior. Para Lev Manovich, por exemplo, essa transformação envolve, em última instância, "[...] a tradução de toda mídia existente em dados numéricos acessíveis por meio de computadores" (2001, p. 20). Temos aí, de fato, um dado essencial: na cibercultura, o valor supremo é a informação representada numericamente. Em outras palavras, a cibercultura promoveu uma radical "informatização" do mundo uma visão na qual toda a natureza, incluindo a subjetividade humana, pode ser compreendida como padrões informacionais passíveis de digitalização em sistemas computadorizados (FELINTO, 2006, p. 4)

Sendo assim, a cibercultura transfere para o mundo virtual o mundo dos homens, numa espécie de "digitalização" da nossa 
cultura, a fim de que se torne possível a interação entre ambos os mundos - o real e o virtual. Nela, a Internet e os demais mecanismos são parte de um imaginário muito particular. Com a popularização da Internet em meados da década de 1990, o acesso tornou-se mais fácil e cada vez mais pessoas passaram a utilizá-la como meio de comunicação, desprendendo-a de sua proposta militar inicial (BARBROOK, 2009). Seu crescimento assinalou o a expansão da informação como objeto de interesse das sociedades mais desenvolvidas, facilitando a velocidade da recepção e transmissão de notícias, a interação entre pessoas de pontos diferentes do mundo, o que, consequentemente, ampliou o conhecimento do homem a respeito da cibercultura, fundamental para o acesso aos benefícios proporcionados dentro deste ambiente. Ou, como disse Pierre Lévy, "o espaço cibernético está se tornando um lugar essencial, um futuro próximo de comunicação humana e de pensamento humano" (2009). O homem passa a criar também dentro deste novo ambiente aquilo que criava fora dele.

Porém, devemos observar que, em parte, o mundo da cibercultura transcende o mundo virtual, chegando a nós através de manifestações artísticas e culturais baseadas neste universo imaginário. A música eletrônica, os filmes de ficção científica que exploram a fusão entre homem e meio cibernético (Matrix, Blade 
Runner - O Caçador de Andróides, Johnny Mnemonic - O Cyborg do Futuro, para citar alguns exemplos), a literatura (como no livro Neuromancer, de William Gibson, que inaugura o termo ciberespaço) inspiraram o surgimento de movimentos urbanos modernos que busca viver esta "realidade" futurista, prevista nestas produções culturais, onde homens e máquinas chegam a se confundir, vivendo num mesmo mundo que nem é completamente real, nem completamente virtual, mas uma mescla entre os dois, proposta por estes elementos midiáticos. O cyberpunk, espécie de movimento subversivo que mistura elementos da cibercultura e do movimento punk, é um dos exemplos desta tentativa de transpor o mundo virtual para o mundo real.

Surgido com o livro de William Gibson, o cyberpunk é contrário às regras impostas pela cultura virtual, desobedecendo-as. No livro, trata-se de um indivíduo imerso num mundo dividido entre humanos e máquinas e que se utiliza de seus conhecimentos tecnológicos para quebrar as barreiras impostas pelas autoridades. Semelhantes a eles, na vida real, são os hackers, indivíduos que, em nome do compartilhamento das informações contidas na rede, capazes de adentrar em ambientes virtuais restritos e policiados por sistemas de segurança considerados invioláveis. Os "cowboys" de Gibson preocupam políticos e banqueiros: 
Cadernos de Clio, Curitiba, $n .^{\circ} 2,2011$

Por trás deste discurso hacker existe uma filosofia. $\mathrm{O}$ conhecimento deve ser livre. Isto é muito diferente da ética protestante, para a qual o dinheiro enobrece o ser humano. De acordo com o jargão hacker ,"a original ética hacker significa a crença que o compartilhamento da informação é um bem um poderoso e positivo." $\mathrm{Na}$ prática isso significa um dever ético de se trabalhar sob um sistema aberto de desenvolvimento, no qual o hacker disponibiliza a sua criação para outros usarem, testarem e continuarem o desenvolvimento (DIMANTAS; MARTINS, 2008, disponível em http://diplo.uol.com.br/2008-02,a2213, acesso em 27 de Julho de 2010)

Os hackers aparecem como indivíduos contrários a uma espécie de privatização da informação, que deve ser restrita a poucos. Para eles, a informação presente na Internet, seja de que natureza for, deve ser pública. Essencialmente, os hackers agem em benefício coletivo, e não individual, da mesma forma que parte do movimento punk passou a pensar no início da década de 1980, quando tornou-se mais politizado. Daí o termo cyberpunk a este tipo de atitude.

Não somente esta interação homem-máquina, como o caso dos hackers, é importante para o historiador como um possível objeto de estudo, mas também a forma como esta interação gera informações a respeito de acontecimentos pertinentes ao estudo da história, como no caso do fascismo. Nos sites visitados durante a pesquisa, pudemos observar a cultura, o comportamento e os modos de agir destes grupos, assim como sua ideologia e as formas como 
ela é apresentada, através da música, de vídeos, panfletos, textos desenvolvidos por ideólogos dos movimentos e até mesmo por membros deles, além da disposição de livros e revistas importantes para estender a propaganda nacional-socialista.

\section{Extreme Violent Racism - A Violência Como Forma De Luta}

"For those with hope, for those with courage, for those who have finally realized that nothing short of a White Revolution will save our race. Supreme White Power, doing whatever it takes for total Aryan Victory." Estes dizeres são o cartão de boas vindas do Extreme Violent Racism (IP: 65.98.56.50). O próprio nome do site (Racismo extremamente violento, em português) deixa clara a sua proposta: combater a presença de negros, judeus e outras minorias na política e na sociedade norte-americana.

Ao adentrarmos no site, em sua página inicial, encontraremos um banner com a fotografia de uma arma de fogo e a frase Powered by hate (ou Movido pelo ódio). Acima, a frase "Revolução branca é a solução final". Mesclando as duas sentenças, podemos concluir que a violência é algo estratégico e importante para grupo idealizador da página em uma esclarecida e explícita luta a favor do racismo. $\mathrm{E}$ ao adentrarmos mais profundamente nas páginas do site poderemos comprovar ainda mais este viés agressivo, 
fundamentado em teóricos nazistas e em propostas políticas nacional-socialistas.

A cada página, encontramos novas provas deste radicalismo violento, além da insistência de que uma revolução é necessária para eliminar completamente os negros da vida do "homem branco", assim como para que a consciência a respeito da importância do nacional-socialismo se faça presente na sociedade norte-americana. Vejamos o trecho a seguir, retirado de uma das postagens do sítio:

Every intelligent individual on the planet predicted Obama's failure and traitorous actions against America's White Working Class, and they were right. In just a few months, he has spent over $\$ 1$ Trillion and is talking about all the gun rights he plans on taking away, while giving rights to illegal mexicans. Maybe all of you out there who have e-mailed me about finally being fed up with "our" government's crooked actions will get off your butts and start becoming racial activists - spread the word.

Axl Hess, codinome do principal autor e dono do site, diz que o atual presidente dos Estados Unidos, Barack Obama, primeiro presidente negro a ser eleito naquele país, traiu a classe operária norte-americana e que isto já era previsível. A traição, segundo o autor, se trata do fato do presidente supostamente ter investido um trilhão de dólares em planos de desarmamento, além de intencionar eliminar os outros direitos armamentistas existentes no país, 
enquanto, em contrapartida, seu governo concede direitos a imigrantes (neste caso, mexicanos) ilegais. A indignação do autor é tamanha que ele aconselha a todos que se sentiram incomodados com as ações do presidente, tomarem partido e tornarem-se "ativistas raciais". Com isso ele busca convencer os militantes neonazistas a praticar atos de violência contra seus "inimigos", promovendo até mesmo atentados, os quais o próprio site ensina a realizar, com manuais práticos e ilustrativos.

O problema da imigração é uma constante no discurso neonazista. Em momentos de grandes crises como o vivido pelos EUA recentemente, as tensões sociais dão origem a este pensamento xenófobo e racista, que funciona como uma válvula de escape para os problemas vividos pelo Estado, e, desta maneira, os estrangeiros, negros, homossexuais e outras minorias, passam a significar pessoas que iriam tomar os empregos, mudar os modos de vida daquele povo, introduzir drogas, criminalidade e decadência para aquela sociedade (VIZENTINI, 2000).

\section{Panfletagem Online}

A propaganda é, definitivamente, a alma do negócio neonazista. O uso dela é de extrema necessidade para que se faça chegar ao maior número possível de pessoas a ideologia racista 
pregada dentro do movimento, um dos principais objetivos deste site. Trata-se de um site voltado quase que exclusivamente à questão racista, e não à repulsa ao comunismo, por exemplo, ou ao controle dos ditos zionistas (judeus) em vários segmentos da sociedade, embora este discurso também apareça; entretanto, seu foco é entusiasmar, ensinar e incentivar as pessoas a violentar as raças que eles, os organizadores do site, jovens nacional-socialistas aparentemente sem muita experiência, supõem ser inferiores.

Porém, há um paradoxo no que diz respeito à propaganda neonazista, e isto é perceptível no próprio website. Enquanto a propaganda se faz necessária para que a palavra nacionalsocialista se espalhe, é necessário que ela se faça de maneira discreta. Portanto, ela deve ser feita de um modo que chegue até os que estão previamente interessados no assunto, pois, caso contrário, poderá atrair autoridades que impeçam a continuidade da ação e possam atém mesmo prender os "agentes" neonazistas. Numa página reservada a instruções de como realizar este tipo de divulgação da idéia racista, os autores do site demonstram onde e como estas informações devem ser transmitidas e para quem; além disso, os encarregados de se aventurar em nome de espalhar a palavra neonazista podem conseguir conselhos e instruções para fugir da 
polícia, de delatores e qualquer um que se coloque no caminho desta "cruzada pelo racismo".

Axl Hess é o maior responsável por este manual virtual sobre como propagar informações a respeito do nacional-socialismo, buscando alcançar seus objetivos. Ele disponibiliza panfletos que podem ser facilmente impressos, contendo ilustrações, frases de efeito, além de estatísticas duvidosas a respeito dos problemas que negros, imigrantes e judeus seriam responsáveis nos Estados Unidos e conclamações inflamadas para que os brancos lutem contra seus "inimigos". Axl também disponibiliza aos visitantes textos fundamentais para entender como a propaganda nazista funciona, incluindo o ensaio chamado Modern Political Propaganda, de Josef Goebbels, ministro da propaganda do Terceiro Reich, um especialista no assunto.

"Eu criei este website com a intenção de fornecer a Racistas Brancos informações sobre o que podemos fazer para garantir efetivamente a existência de nosso povo." Este trecho abre a página de boas-vindas do site Extreme Violent Racism, parte de um longo texto enfatizando seus propósitos, também escrito por Axl Hess. Mais adiante podemos ler: "Esta é a hora de lutar!" e, logo em seguida, a frase "Deus deu à Raça Branca o cérebro para fazer armas, mas ele não irá puxar o gatilho por você." Não é preciso muito 
esforço para compreender o viés declaradamente racista e violento que o site propõe aos seus visitantes. Fica claro ao lermos toda a declaração desta página que a intenção é abandonar as formas pacíficas de luta pelo poder e contra os negros e judeus e assumir que apenas através da violência, ou de uma espécie de guerra, será possível chegar a estes objetivos.

Para que os brancos possam sobreviver a esta guerra, o site disponibiliza manuais de luta urbana, de como se defender, evitar prisões, fabricar armamentos caseiros e realizar treinamentos físicos, a fim de que os "soldados arianos" possam realizar sua luta de maneira eficaz. Esta guerra proposta pelos idealizadores do site é fundamentada por diversos documentos, artigos e livros dispostos na própria página, incluindo uma versão em PDF de "Minha Luta", escrito por Adolf Hitler enquanto esteve preso, anos antes de tomar o poder na Alemanha. Para alguns neonazistas, a Segunda Guerra não terminou com a derrota dos alemães, ela ainda continua e sua direção deve ser revertida a todo custo.

\section{Considerações Finais}

Através da Internet, grupos de extrema-direita vem propagando o racismo, a xenofobia e a busca por um retorno do nacional-socialismo, aproveitando-se do fácil manuseio que este 
mecanismo possibilita e o seu longo alcance, num mundo onde a globalização se faz a cada dia também através da rede (BARBROOK, 2009). A rede mundial de computadores nos serviu, nesta pesquisa, como um portal para as informações que, uma vez cuidadosamente estudadas e confrontadas com outras fontes de conhecimento histórico, nos possibilitou a compreensão de que, ao contrário do que se pensava, o fascismo ressurge diante de nossos olhos e não é apenas um fenômeno de um passado distante, que deve ser esquecido, como algo exclusivo daquele tempo histórico (PAXTON, 2007).

Diariamente milhares de acessos são realizados nestes websites e a participação é grande, o que demonstra que o interesse por eles é significativo, o suficiente para percebermos que o fascismo ainda se mantém presente e ganhando novos adeptos a cada clique. Conhecer a ação destes grupos é entender que o fascismo sobreviveu à Segunda Guerra Mundial, tornou-se minoritário, porém muito grande, e espalhou-se pelo mundo inteiro. Eventos como a queda do Muro de Berlim (1989), o desmantelamento do bloco socialista com o fim da União Soviética (1991) e as crises nos Estados Unidos no último ano são propícios ao ressurgimento de partidos de extremadireita com plataformas conservadoras e nacionalistas, que culpam estrangeiros, negros e outras minorias pelas mazelas da sociedade, 
como uma forma de desviar o olhar da sociedade dos problemas reais.

Quando, após 1991, o experimento pós-soviético com a democracia eleitoral e a economia de mercado trouxe resultados desastrosos para a Rússia, movimentos como o Paymat ("memória") resgatam essa rica tradição eslavófila, agora atualizada com elogios explícitos à experiência nazista (PAXTON, 2007, p. 308).

A crise traz ao povo o desespero, e movimentos de extremadireita, como o Paymat, na Rússia, tentam explicar esta crise utilizando concepções que não são necessariamente seguras ou possuem um fundamento concreto. Levada a acreditar que os problemas sociais vividos são realmente aqueles, tal sociedade acaba considerando as opiniões destes grupos ou partidos políticos, uma vez que, aparentemente, nem o capitalismo, nem o socialismo (já derrubado) resolveram os seus problemas (PAXTON, 2007). A Internet junta o mundo, e com isso pessoas da América do Sul se identificam com o que acontece na Europa, ou na América do Norte, se tal crise ou tal acontecimento político, social ou econômico for semelhante à que vive em tal situação. Estes sites são catalisadores desta identificação com o nacional-socialismo: se já existe no indivíduo que os visita uma pré-disposição para aceitar o que as páginas dispõem, ele se tornará facilmente influenciado. 
Cadernos de Clio, Curitiba, . $^{\circ}$ 2, 2011

\section{Referências Bibliográficas}

BARBROOK, Richard. Futuros imaginários: das máquinas pensantes à aldeia global. São Paulo: Peirópolis, 2009.

Blood \& Honour USA < http://bloodandhonour-usa.com>

CASTELLS, Manuel. A Galáxia da Internet. Rio de Janeiro: Jorge Zahar Editor, 2003.

DIEHL, Astor Antônio. Em busca de uma definição. In: Do método histórico. 2ed. Passo Fundo, RS: UPF, 2001. p. 19 -31.

DIMANTAS, Hernani; MARTINS, Dalton. A Cultura Hacker. Disponível em: <http://diplo.uol.com.br/2008-02,a2213>, acessado em 27 de janeiro de 2010.

Extreme Vilent Racism <http://www.whitehonor.com/>

FELINTO, Erick. Os computadores também sonham? Para uma teoria da Cibercultura como imaginário. Intexto, Porto Alegre: UFRGS, v. 2, n.15, p. 1 - 15. Julho/Dezembro 2006. <http:/ /www.seer.ufrgs.br/index.php/intexto/article/view/4257> Acesso em 20 de dezembro de 2009.

FRANK, Robert. Questões para as fontes do presente. In: CHAUVEAU, Agnès; TÉTART, Philippe (Org.). Questões para a história do presente. Tradução: Ilka Stern Cohen. São Paulo: Edusc, 1999.

GIBSON, William. Neuromancer. São Paulo: Editora Aleph, 2003. 
GRESPAN, Jorge. Considerações sobre o método. In: PINSKI, Carla B (Org). Fontes Históricas. São Paulo: Contexto, 2005. p. 300. LAGROU, Pieter. A História do Tempo Presente na Europa depois de 1945 - Como se constituiu e se desenvolveu um novo campo disciplinar. Rio de Janeiro: Revista Eletrônica Boletim do tempo, ano 4, $n^{\circ}$. 15. Rio de Janeiro, 2009 [ISSN 9181-3384]. MARQUES, Adhemar Martins, BERUTTI, Flávio Costa, FARIA, Ricardo Moura. Textos e documentos 7: História do tempo presente. São Paulo: Contexto, 2007.

Metapedia $<$ http://www.metapedia.org $>$ MILMAN, Luís, VIZENTINI, Paulo F. (Orgs.) Neonazismo, negacionismo e extremismo político. Porto Alegre: Editora UFRGS, CORAG, 2000.

PAXTON, Robert. A anatomia do fascismo. Trad. Patrícia Zimbres e Paula Zimbres. Rio de Janeiro: Paz e Terra, 2007. p. 283-312. SILVA, F.C. Teixeira da. O Século Sombrio: uma história geral do século XX. Rio de Janeiro: Elsevier, 2004. 